\title{
Peertechz
}

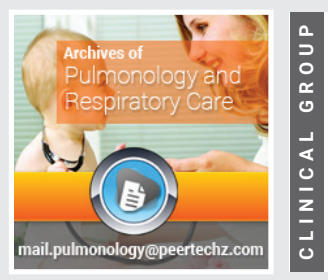

\section{Acupuncture-Induced Pneumothorax: A Recurring Problem}

\author{
Farhat Mushtaq ${ }^{1 *}$ and Louise Polson² \\ ${ }^{1}$ Consultant in Emergency Medicine, Emergency Department, Hairmyres Hospital, East Kilbride, United \\ Kingdom \\ ${ }^{2}$ General Practitioner, NHS Highlands, UK
}

Received: 24 June, 2020

Accepted: 30 July, 2020

Published: 31 July, 2020

*Corresponding author: Farhat Mushtaq, Consultant in Emergency Medicine, Emergency Department, Hairmyres Hospital, East Kilbride, United Kingdom, Tel: 01355 584728;

E-mail: Farhat.mushtaq@lanarkshire.scot.nhs.uk

Keywords: Emergency medicine; Pneumothorax; Acupuncture; Informed consent; Alternative medicine

https://www.peertechz.com

Check for updates

\section{Abstract \\ Complications related to acupuncture can have significant consequences for the patient as described in our case report below. However we believe that patients are not made aware of these complications and therefore we would like to see changes made to the way acupuncture is practiced in the United Kingdom.}

\section{Introduction}

Acupuncture is generally thought to have originated from China well over 2000 years ago [1]. It is a common alternative therapy sought by patients in order to alleviate a variety of symptoms ranging from headaches, musculoskeletal problems to infertility and anxiety [2]. It is generally thought of as a safe procedure with only minor risks when performed correctly by a trained practitioner. However acupuncture can be associated with serious complications [3]. One of these complications is a pneumothorax as discussed in our case study below.

\section{Case study}

A 41 year old lady due to emigrate to South Africa the following day by a long haul flight attended an Osteopathy service with chronic back pain at 1400 hrs. She was treated with a combination of manual therapy and acupuncture of unknown needling depth into the rhomboids, thoracic erector and supraspinatus areas.

She re-presented to the Osteopathy service two hours after discharge complaining of chest and back pain. The pain had started immediately after the acupuncture session and had been increasing in severity since. As the pain failed to be controlled by 'soft tissue techniques' the patient was advised to attend the hospital 'due to a risk of pneumothorax after acupuncture'.
The patient presented to University Hospital Hairmyres Emergency Department at 2200hrs complaining of shortness of breath and central pleuritic chest pain. She was noted to be systemically well with normal observations. Examination revealed reduced air entry in the right apex.

A chest radiograph confirmed the clinician's suspicions of an acupuncture induced by pneumothorax (Figure 1). ECG and laboratory investigations were normal.

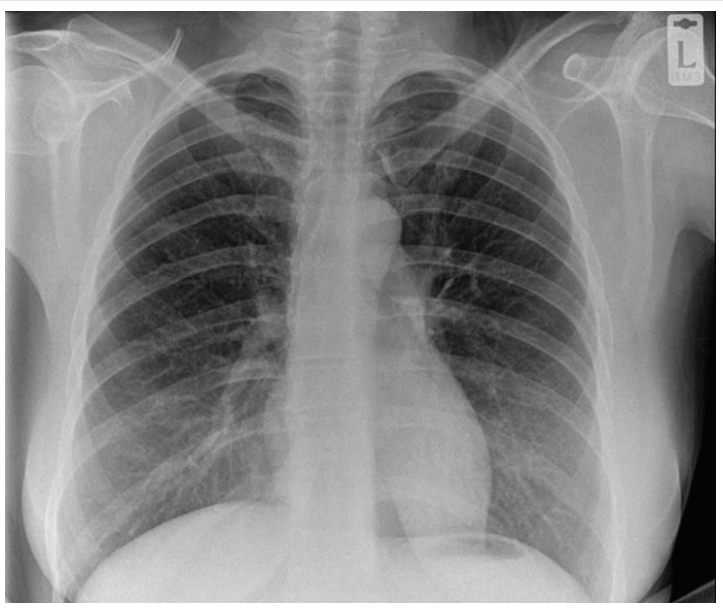

Figure 1: Acupuncture Pneumothorax. 
Due to the size of the apical pneumothorax a decision was made to treat it conservatively. The patient was admitted overnight for observation. As the patient remained well, she was discharged the next morning with follow up arranged in one week for a repeat CXR to ensure resolution of the pneumothorax.

The patient was also advised that she would be unable to fly for a further 6 weeks as per the Civil Aviation Authority guidelines.

\section{Discussion}

Acupuncture is becoming increasingly more common in the Western society, with many patients choosing alternative therapies to manage their health issues. This is despite it being recommended by NICE as a treatment option only for migraines and tension-type headaches [4]. Musculoskeletal pain and stress are two of the most common reasons for patients taking time off of work [5]. Unsurprisingly these two reasons are also cited repeatedly by patients as their reason for having acupuncture [6].

The first recorded case of acupuncture-related pneumothorax was in 1956. Since then there have been numerous studies and case reports detailing the potential adverse effects of acupuncture [3,7,8], including infection, bleeding and pneumothoraces. While pneumothoraces caused by acupuncture are reported to be rare, it is likely that the true incidence is grossly under-reported.

Potential reasons for under reporting of pneumothoraces post acupuncture may be inadequate patient information regarding potential side effects, failure by the emergency physicians to enquire about acupuncture for all patients presenting with pneumothorax and the time taken for symptoms to develop.

It is concerning that a video on the British Acupuncture Council website states that there are 'virtually no adverse side effects after acupuncture'. In addition it calls acupuncture induced pneumothorax an 'urban myth'. This second statement in particular is highly controversial, given that there is evidence to the contrary. A consent leaflet the British Medical Acupuncture Society provides to patients states that 'serious side effects are very rare' without detailing what these side effects may be. This makes fully informed consent unlikely [9]

Anecdotally in our ED in the recent years, there have been at least 3 cases of acupuncture induced pneumothorax that the authors are aware of [10]. One of these patients died as a result of complications related to their acupuncture induced pneumothorax.

It has been proven that when acupuncture is performed by untrained practitioners there are increased risk of side effects [8]. Despite this, there is still no statutory regulation of acupuncturists in the UK. Individual practitioners only have to register with their local authority without having to provide proof of qualifications or evidence of continuous professional development.
It is vital that comprehensive training programs are introduced for all trainee and trained acupuncturists with focus on anatomy, depth and direction of needle insertion. This is especially important over the lower neck and thoracic area to prevent potential pleural injuries. Alternatively acupuncture points distant to major organ sites should also be considered during acupuncture sessions.

Introduction of statutory regulation for acupuncturists will have the dual benefit of ensuring that registration and fitness to practice is maintained whilst providing acupuncturists with protection and support. It will also provide the additional benefit of transparency of potential complications related with procedures performed and an ability to learn from these.

In the case presented, it has been demonstrated how a simple acupuncture session for the patient resulted in far reaching consequences.

\section{Learning points}

In future we would like the patients to be aware of potential complications including pneumothorax prior to undergoing acupuncture therapy. In addition we believe that the cases we have seen are only the 'tip of the iceberg'. We would therefore like ED staff to be more aware of the link between acupuncture and pneumothorax.

Finally we believe that there needs to be UK wide regulatory body to which all acupuncturists must be registered in order to ensure patient safety.

\section{Funding}

This case report received no specific grant from any funding agency in the public, commercial or not-for-profit sectors.

\section{References}

1. White A, Ernst E (2004) A Brief History of Acupuncture. Rheumatology 43: 662 663. Link: https://bit.ly/2Xrnbbh

2. Hopton AK, Curnoe S, Kanaan M, MacPherson H (2012) Acupuncture in practice: mapping the providers, the patients and the settings in a national cross-sectional survey. BMJ Open 2: e000456. Link: https://bit.ly/3hMzHtx

3. Kim MR, Shin JS, Lee J, Lee YJ, Ahn YJ, et al. (2016) Safety of Acupuncture and Pharmacopuncture in 80523 Musculoskeletal Disorder Patients. Medicine 95 : e3635. Link: https://bit.ly/3jSw0t1

4. National Institute for Health and Care Excellence (2018) Migraines. Link: https://bit.ly/2CSJ644

5. National Institute for Health and Care Excellence (2017) Headache - tensiontype. Link: https://bit.ly/3gedtQD

6. Sickness absence in the UK labour market (2016) Sickness absence rates of workers in the UK labour market, including number of days lost and reasons for absence. Office for national statistics. 9th $^{\text {th }}$ March 2017. Link: https://bit.ly/2DmAse0

7. Wenju H, Zhao X, Qiang X, Guo Y (2012) Adverse Events Following Acupuncture: A Systematic Review of the Chinese Literature for the Years 1956-2010. Altern Complement Med 18: 892-901. Link: https://bit.ly/39Hcypw

Citation: Mushtaq F, Polson L (2020) Acupuncture-Induced Pneumothorax: A Recurring Problem. Arch Pulmonol Respir Care 6(1): 062-064. 
8. Xu S, Wang L, Cooper E, Zhang M, Manheimer E, et al. (2013) Adverse Events of Acupuncture: A Systematic Review of Case Reports. Evid Based Complement Alternat Med 2013: 581203. Link: https://bit.ly/3hNMUSP
9. Link: https://bit.ly/3jYfG5g

10. Brogan R, Mushtaq F (2015) Acupuncture-Induced Pneumothorax: The Hidden Complication. Scottish Medical Journal 60: e11-e13. Link: https://bit.ly/2CSzUg3

\section{Discover a bigger Impact and Visibility of your article publication with}

\section{Peertechz Publications}

\section{Highlights}

* Signatory publisher of ORCID

* Signatory Publisher of DORA (San Francisco Declaration on Research Assessment)

* Articles archived in worlds' renowned service providers such as Portico, CNKI, AGRIS, TDNet, Base (Bielefeld University Library), CrossRef, Scilit, J-Gate etc.

* Journals indexed in ICMJE, SHERPA/ROMEO, Google Scholar etc.

* OAI-PMH (Open Archives Initiative Protocol for Metadata Harvesting)

* Dedicated Editorial Board for every journal

* Accurate and rapid peer-review process

* Increased citations of published articles through promotions

* Reduced timeline for article publication

Submit your articles and experience a new surge in publication services (https://www.peertechz.com/submission).

Peertechz journals wishes everlasting success in your every endeavours.

Copyright: @ 2020 Mushtaq F, et al. This is an open-access article distributed under the terms of the Creative Commons Attribution License, which permits unrestricted use, distribution, and reproduction in any medium, provided the original author and source are credited. 